\title{
e 3 Things to Consider Before Relying Solely on Point of Care Tests for Determining Benzodiazepine Use in Chronic Pain
}

\section{To The EDITOR:}

We read with interest the article titled "Comparative Evaluation of the Accuracy of Benzodiazepine Testing in Chronic Pain Patients Utilizing Immunoassay with Liquid Chromatography Tandem Mass Spectrometry (LC/MS/MS) of Urine Drug Testing" (1). Having provided the analytical information used as the basis for the article, we felt it important to relate information to your readers that may be of further benefit.

Although the dangers of benzodiazepine use and overuse among the pain patient population were clearly stated, it was suggested that patients who have been prescribed benzodiazepines who test positive for them on point of care tests do not require additional testing by LC-MS/MS. We disagree with this suggestion and offer the following to support our position.

As many of your readers who use point of care devices are aware, the immunoassays on these devices only indicate whether the patient is positive or negative for the benzodiazepine class. That is, point of care tests cannot determine which benzodiazepine the patient is taking or, more importantly, if the patient is taking multiple benzodiazepines.

We are not suggesting that it is necessary to send all positive benzodiazepine point of care specimens for further testing; some providers may wish to only send specimens from specific patient populations, such as those who exhibit aberrant behavior, or those at high risk for controlled substance abuse (2).

An unexpected urine drug test (UDT) result demonstrating positive results for multiple benzodiazepines provides an opportunity to further explore the potential underlying reasons. Numerous reasons may exist for this type of unexpected UDT result, including self-treatment of anxiety with an alternative benzodiazepine, self-treatment of another symptom (e.g., insomnia) with an alternative benzodiazepine, and/or duplicate therapy due to lack of patient knowledge regarding which medications are benzodiazepines (e.g., lorazepam for anxiety, temazepam for sleep). In many of these cases patients may not fully recognize the po- tential risk. However, point of care tests alone will not identify such use or outcomes; only further laboratory testing will provide information that elucidates potentially dangerous duplicate therapy (prescribed or nonmedical use) with benzodiazepines.

To reference the same data from the study your article was based on, of the patients who were positive for the benzodiazepine class by Point of Care immunoassay, when tested by LC-MS/MS, 15\% were found to be taking additional benzodiazepines compared to those reported as prescribed by their provider.

Those patients may not wish for their physician to know they are self-medicating with benzodiazepines other than what they are "supposed" to be taking, but it is certainly in their best health interest for their physician to know.

On another note, in your article it is suggested that patients who test negative by point of care device for benzodiazepines, and who have not been prescribed those drugs, do not require further laboratory testing by LC-MS/MS. We believe the data may suggest otherwise, and this leads to the second point of use to your readers.

In the study upon which your article was based, $6 \%$ of the patients who were not prescribed benzodiazepines were found to be taking them (1). This percentage increased by $50 \%$ to $9 \%$ of patients when analysis was conducted by LC-MS/MS. (Note: in our studies of hundreds of thousands of patients we find $15 \%$ of the population to be using nonprescribed benzodiazepines.) This suggests that somewhere between 9 and 15 out of every 100 pain patients are taking non-prescribed benzodiazepines.

In light of this demonstrated ability to reduce the incidences of false negative results at the point of care, we believe physicians should carefully consider whether sending specimens for further testing by LC-MS/MS may be the better course to minimize patient risk, at least for certain higher risk patients.

The third point of information we'd like to men- 
tion is that the immunoassays used in point of care tests do not tell the physician which benzodiazepine a patient is taking, only that he or she is positive or negative for the benzodiazepine class of drugs. As the physician treating patients with the potent and delicate mix of opiates and benzodiazepines, it would seem that identifying which benzodiazepine a patient is taking would be of as much value as knowing exactly which opiate the patient is taking. This can only be achieved by conducting further analysis with LC-MS/MS. Why?

We already established the value to the patient's health by identifying the use of nonprescribed benzodiazepines. Beyond this, knowing specifically which benzodiazepine the patient is taking provides the physician with valuable information when reviewing the patient's medications with them to determine if they are getting adequate relief from their symptoms.

As stated in the article about which this letter is being written, drug testing adds to the cost of care. However, in a newly released study, urine drug testing, including laboratory quantification, demonstrates the positive cost benefit of UDT as determined by LC-MS/ MS (3).
It is ultimately up to each physician to assess on a case by case basis the clinical value, risks, and benefits for conducting urine drug testing. As the title of this letter indicates, we have offered your readers 3 evidencebased considerations when making the most informed decision possible when testing for benzodiazepines.

\author{
Charles Mikel, PhD \\ Millennium Laboratories \\ 16981 Via Tazon \\ San Diego, CA \\ E-mail: cmikel@becausepainmatters.com \\ Amadeo Pesce, PhD \\ Millennium Laboratories \\ 16981 Via Tazon \\ San Diego, CA 92127 \\ E-mail: pesceaj@ucmail.uc.edu \\ Cameron West, PhD \\ Millennium Laboratories \\ 16981 Via Tazon \\ San Diego,. CA 92127 \\ E-mail: cwest@becausepainmatters.com
}

\section{References:}

1. Manchikanti L, Malla Y, Wargo BW, Fellows B. Comparative evaluation of the accuracy of benzodiazepine testing in chronic pain patients utilizing immunoassay with liquid chromatography tandem mass spectrometry (LC/MS/MS) of urine drug testing. Pain Physician 2011; 14:259-270.
2. Gourlay DL, Heit HA, Almahrezi A. Universal precautions in pain medicine: $A$ rational approach to the treatment of chronic pain. Pain Med 2005; 6:107-112.

3. Laffer A, Murphy R, Wingarden W, Pesce A, Mikel C, West C, Egan-City K, Strickland J, Christie J. An Economic Analysis of the Costs and Benefits Associated with Regular Urine Drug Testing for Chronic Pain Patients in the United States. Laffer Associates and Millennium Research Institute: Washington D.C., August 2011.

\section{In Response: 3 Things to Consider Before Relying Solely on Point of Care Tests for Determining Benzodiazepine Use in Chronic Pain}

\section{TO THE EDITOR:}

We appreciate Dr. Pesce's and West's comments on the manuscript. As they have illustrated, they were involved in the laboratory testing of the data of our publications (1-3). It appears that, they contend, based on $5 \%$ to $9 \%$ of patients using alternative benzodiazepine, essentially we should send all the tests to the lab. 
For this, they also quote a study conducted by Laffer et al (4) which is part of Millennium Research Institute, part of Millennium Laboratories. This is considered not based on evidence and as promoting the urine drug industry by many. Further, a recent manuscript essentially shows that urine drug testing is not the practice of medicine; rather, it is a business model for profit centers (5).

Overall, considering the issues related to exploding health care costs and physicians' ability to provide any type of service based on the costs, it is essential to take a conservative approach with patient's history and drug testing results performed in the office. Even though,drug testing has become a cottage industry costing numerous health care dollars and resulting in significant curtailing of access to these drugs, a costeffective and clinically effective approach is the one we have suggested in our manuscript (6).

Laxmaiah Manchikanti, MD

Associate Clinical Professor

Anesthesiology and Perioperative Medicine

University of Louisville, Kentucky

\author{
Medical Director \\ Pain Management Center of Paducah \\ Paducah, Kentucky \\ Yogesh Malla, MD \\ Interventional Pain Physician \\ Pain Management Center of Paducah \\ Paducah, Kentucky \\ Bradley W. Wargo, DO \\ The McFarland Clinic \\ Mary Greeley Medical Center \\ Department of Pain Medicine \\ Ames, lowa \\ Bert Fellows, MA \\ Director Emeritus of Psychological Services \\ Pain Management Center of Paducah \\ Paducah, Kentucky
}

\section{References}

1. Manchikanti L, Malla Y, Wargo BW, Fellows B. Comparative evaluation of the accuracy of benzodiazepine testing in chronic pain patients utilizing immunoassay with liquid chromatography tandem mass spectrometry (LC/MS/MS) of urine drug testing. Pain Physician 2011; 14:259-270.

2. Manchikanti L, Malla Y, Wargo BW, Cash KA, Pampati V, Damron KS, McManus $C D$, Brandon DE. Protocol for accuracy of point of care $(P O C)$ or in-office urine drug testing (immunoassay) in chronic pain patients: A prospective analysis of immunoassay and liquid chromatography tandem mass spectometry (LC/MS/ MS). Pain Physician 2010; 13:E1-E22.

3. Manchikanti L, Malla Y, Wargo BW, Fellows B. Comparative evaluation of the accuracy of immunoassay with liquid chromatography tandem mass spectrometry (LC/MS/MS) of urine drug testing (UDT) opioids and illicit drugs in chronic pain patients. Pain Physician 2011; 14:175-187.

4. Laffer A, Murphy R, Wingarden W, Pesce A, Mikel C, West C, Egan-City K, Strickland J, Christie J. An Economic Analysis of the Costs and Benefits Associated with
Regular Urine Drug Testing for Chronic Pain Patients in the United States. Laffer Associates and Millennium Research Institute: Washington D.C., August 2011.

5. Collen M. Profit-driven drug testing. J Pain Palliat Care Pharmacother 2012; Feb 13 [Epub ahead of print].

6. Christo PJ, Manchikanti L, Ruan X, Bottros $M$, Hansen $H$, Solanki D, Jordan AE, Colson J. Urine drug testing in chronic pain. Pain Physician 2011; 14:123-143. 